\title{
Creating context with prebriefing: A case example using simulation
}

\author{
Dana E. Brackney *, Kimberly S. Priode \\ Department of Nursing, College of Health Sciences, Appalachian State University, Boone, United States
}

Received: September 26, 2014

Accepted: October 29, $2014 \quad$ Online Published: November 11, 2014

DOI: $10.5430 /$ jnep.v5n1p129

URL: http://dx.doi.org/10.5430/jnep.v5n1p129

\begin{abstract}
Background: Educational advantages of simulation have been widely reported. Pre-briefing and debriefing support simulation methods. However, few detailed accounts of how the learning activities surrounding simulation are implemented exist.

Objectives: This case example provides a detailed description of learning activities surrounding a simulation experience with a deteriorating cardiac patient. The educational sequence integrates Benner et al.'s goals for transforming nursing education. The study objectives were to design and evaluate an educational sequence using narrative, games, and simulation to teach students how to manage and anticipate the care of a deteriorating patient.

Design: A case example with descriptive quantitative and qualitative evaluation is presented. Setting: The study took place on multiple days in a university simulation laboratory. Participants: All study participants $(n=43)$ were senior students enrolled in a Bachelor of Science in Nursing program.

Methods: Students experienced an educational sequence and then rated and ranked educational activities. Results are reported with descriptive statistics. Students and faculty responded to the question, "What will you take from this experience?" Their responses were evaluated using constant comparison and expert review for themes.

Results: Students identified 'knowing how', 'increasing confidence' and 'understanding roles' as what they took from the experience. Students ranked the simulation itself as the most helpful.

Conclusions: Incorporating Benner et al.'s transformational educational goals informed the educational sequence and engaged students in the learning experience. This paper adds uniquely to the nursing literature by providing detailed accounts of the activities surrounding simulation that support student learning in multiple domains.
\end{abstract}

Key Words: Patient simulation, Nursing education, Perceptions

\section{Introduction}

Simulation is an educational technique that can create situated learning experiences for nursing students. The educational advantages of simulation have been widely reported. ${ }^{[1-3]}$ Researchers generally agree that pre and post simulation briefing and debriefing are essential for the meaningful application of simulation. ${ }^{[4-6]}$ However, few detailed accounts of the implementation of learning activities surrounding simulation have been reported. Simulation is time-intensive for faculty; therefore, structuring the simulation scenarios to advance student performance is essential for responsible use of this limited resource. Scenar-

\footnotetext{
* Correspondence: Dana E. Brackney; Email: brackneyde@appstate.edu; Address: Department of Nursing, College of Health Sciences, Appalachian State University, ASU Box 32151, North Carolina, United States.
}

Published by Sciedu Press 
ios asking the nurse to respond to the deteriorating patient are important and applicable to many care settings. Fischer and $\mathrm{King}^{[7]}$ identified a need for more research regarding the use of simulation in educating student nurses to respond in emergencies. Further, Bogossian et al ${ }^{[8]}$ with The FIRST2ACT ${ }^{\mathrm{TM}}$ research team determined that 9 of $97(1 \%)$ students performing in a deteriorating patient scenario met the passing level on clinical performance. They conclude that final year nursing students have difficulty recognizing and responding to patient deterioration and recommend educational activities that specifically address clinical performance, teamwork and situation awareness.

This study provides a detailed description of learning activities surrounding a simulation experience with a deteriorating cardiac patient and employs pre-briefing, simulation, and post-briefing experiences. In 2010, Benner, Sutphen, Leonard and Day ${ }^{[9]}$ presented four overarching goals for transforming nursing education: 1) implement a sense of situated cognition, for salience and action in particular nursing care situations; 2) integrate clinical and classroom teaching; 3 ) emphasize clinical reasoning and multiple ways of thinking; and 4) use experiential learning to form a professional identity. All four of these goals were integrated into the design of this a simulation learning sequence.

\section{Research questions}

The purpose of this descriptive study was to apply Benner et al.' ${ }^{[9]}$ recommendations for transforming nursing education to the design of an educational sequence and measure students' perceived benefit from each component. Simulation activities ranging from low to high fidelity were incorporated to engage multiple educational domains from both a constructivist and behaviorist pedagogy. These activities included decision making, problem solving and prioritizing, nursing skill performance, awareness of personal feelings and attitudes, and teamwork. The research question regarding the student experience was, "What do nursing students perceive as beneficial to their learning?" The research question regarding the faculty experience was, "What influence did pre-briefing have on the student experience?"

\section{Method}

This descriptive study examined a single case example of a simulation integrated learning sequence. The forty-four female students who experienced the educational sequence were 22 to 24 years of age, from the southeastern United States, and were enrolled in a senior level Adult Health III Baccalaureate nursing course. The simulated integrated learning sequence is described in detail below and includes six activities designed to address all four of Benner et $a l .{ }^{\text {'s }}{ }^{[9]}$ goals for transforming nursing education. Student rankings and ratings described the student perception of benefit for five of the educational activities. The sixth ac- tivity, medication review, was added in response to student performance and was not part of the data collection. Five students did not rank the activities using a one to five scale and those responses were not included in the numeric description. Therefore, a total of 38 valid evaluations were included in this analysis. The descriptive ratings and rankings were compiled into tables and will be discussed in the context of other published research findings. In addition to the descriptive ratings and rankings, student and faculty responded to the question, "What will you take from this experience?" These responses were written immediately following the two-hour simulation. The written self-reported benefits of the experience and recommendations for future learning activities were categorized using constant comparison and reviewed with a content expert to confirm thematic groupings. The documented results include a report of the faculty's response to the experience.

\subsection{Ethical considerations}

This study was submitted to the university's ethics board and approved with an IRB exemption. All students participated in the simulation and educational learning sequence as partial fulfillment of course work. Students could choose whether or not to complete the evaluation form, without penalty, as faculty did not include the study's evaluation form as part of the Adult Health III course simulation experience. Forty-three of 44 students who experienced the learning sequence participated in the research study by completing the evaluation of their experience.

\subsection{Description of the learning sequence}

Faculty sequenced six learning activities to create an integrative educational experience aimed at preparing nursing students to respond to a deteriorating patient experiencing a cardiac emergency. During the pre-briefing, faculty provided students with the following objectives. "The student will perform assessment of the cardiac and respiratory system in a nursing context. The student will identify the following cardiac rhythms by reading electrocardiogram (EKG) strips: Normal Sinus Rhythm, Sinus Bradycardia, Sinus Tachycardia, Ventricular Fibrillation, Ventricular Tachycardia, Atrial Fibrillation, and Premature Ventricular Contractions (PVC). The student will identify respiratory distress. The student will identify common emergencies associated with the following medical diagnoses/symptoms: Chest pain, Dehydration, Diabetes, Chemical Exposure, Pneumonia, Pulmonary Embolism, Sepsis, and Bleeding. The student will experience a cardiac and respiratory code. The student will know and experience the following nursing roles in a code (primary care nurse, airway manager, cardiac manager, medication administrator, recorder)."

Faculty used the six learning activities to meet the learning objectives. These activities included 1) a first year nurse's reflection of his/her first experience of a code; 2) cardiac as- 
sessment practice including recognition of cardiac rhythms with a high fidelity mannequin; 3) use of a Q-sort style worst case scenario game to apply the Advanced Cardiac Life Support (ACLS) "Hs and Ts" (The Hs and Ts consist of the following symptoms and conditions: hypovolemia, hypoxia, hydrogen ion (acidosis), hyper-/hypokalemia, hypoglycemia, hypothermia, toxins, taponade (cardiac), tension pneumothorax, thrombosis (coronary and pulmonary), and trauma.); 4) a 4-minute megacode video segment and discussion of the roles of code team members; 5) performance in a high-fidelity emergency simulation with debriefing; and 6) review of common emergency medications and their administration. Each senior level nursing student (n $=44$ ) experienced these activities once during a two hour "Emergency Simulation". Each activity received the following time allocations: Introduction to simulation with narrative (15 minutes); Assessment of heart and lungs with a review using SimMan3G ${ }^{\circledR}$ (15 minutes); Worst case scenario: Anticipating potential emergencies (15 minutes); Code Video and discussion of nurses' roles (15 minutes); Code simulation and debrief including medication purpose and administration (60 minutes); Evaluation (5 minutes). The faculty delivered the learning sequence eleven times over a 5 week period as part of the Adult Health III course. Forty-three of the 44 students agreed to participate in the research study by completing the evaluation. Each of the 11 groups consisted of three to five students with the majority (9 of 11) having four students. Objectives and activities were kept constant from group to group. However, adaptations often occur in simulations in response to student behaviors and faculty tailored the learning activities based on identified gaps in student understanding.

\subsubsection{Reflection on a first code - situated cognition}

In order to implement Benner et al.' ${ }^{[9]}$ transformational educational component, situated cognition, the faculty integrated and discussed a Registered Nurse's (RN's) firsthand account of a cardiac arrest with students. Registered Nurses enrolled in an online Bachelor of Science in Nursing (BSN) program wrote about critical incidents they experienced in their nursing practice. With student permission, faculty selected critical incidents written by RN to BSN students to illustrate course concepts in the pre-licensure program. Each group of students read and discussed the following new graduate $\mathrm{RN}$ reflection on a first code:

My second week on the floor, I was taking care of a patient who had an extensive cardiac history and was visibly very sick. I now can look back and see all of the signs pointing to what was about to happen, but at the time I was just mildly concerned. In report, I was told she had a prolonged QT, but that she was taking Amiodarone so it wasn't too strange. She also had a pacemaker/defibrillator, but she had developed an irregular heart rate during her stay so we weren't sure if it was working properly. When I spoke to her, she told me she was 'filling up with fluid' and she didn't feel well. Her blood pressure and temperature spiked about $30 \mathrm{~min}$ utes before it happened, and she became terribly nauseated and diaphoretic. She looked just awful, and I could tell something was wrong, but didn't realize the severity. Then, during the hustle and bustle of moving two patients to surgery, I went to the telemetry desk just to check on everyone, and she went into $\mathrm{v}$ tach. I don't think I will ever forget the feeling I had when I saw those beats. I ran to her room, where I found her gasping and her husband was beside himself with fear. At first, she had a very weak pulse. We called a rapid response, but it quickly turned to a code when we lost pulse and began CPR.

Luckily, she survived and was transferred to the unit. I felt terribly sick after everything was finished, but since then I've realized how much this event has taught me. It was my first code ever, and it made me realize that if I think something is wrong with a patient, something very well may be wrong. I didn't want to trust my feelings because I am such a new nurse, and figured I am just anxious about anything because I don't have experience. That woman was very sick, though, and since then I have intervened earlier on patients I just didn't feel right about. It's important to follow your gut in nursing, and I am just glad that the woman who taught me that lesson survived the teaching!

Students were asked to read this reflection and answer the following questions.

(1) What could this nurse have done when he/she was mildly concerned?

(2) What was the symptom that first should have brought action? What might that action have been? Anything else concerning? What was happening physiologically?

(3) How do you feel about being involved in a code?

(4) How might you cope with concerns? Do you trust your assessment?

Student questions were answered and student understandings of the scenario were explored. For faculty, this activity provided insight into how the student might approach and/or react to the emergent situation. One student surprised faculty by exclaiming, "You cannot prevent a code. If it is going to happen it is going to happen." Discussion invariably included how a nurse who identified symptoms 
of deterioration could prevent a code. Students and faculty discussed alternative actions a nurse could perform in the aforementioned scenario. In this way, faculty applied Benner et al.'s ${ }^{[9]}$ concept of situated cognition and aided the forming of the students' identity as a proactive nurse. The use of clinical reasoning and multiple ways of thinking were also emphasized during this activity.

\subsubsection{Practice and review of cardiac assessment - inte- grating classroom and clinical teaching}

Following completion of the reflection on a first code the students worked with SimMan $3 \mathrm{G}^{\mathrm{R}}$, a high fidelity mannequin. They performed a cardiac assessment including identification of eight different cardiac rhythms. The senior nursing student was expected to recognize normal sinus rhythm, sinus bradycardia, sinus tachycardia, atrial tachycardia, atrial fibrillation, ventricular tachycardia, ventricular fibrillation, and asystole. In addition, faculty demonstrated the emergency equipment used in a cardiac and respiratory arrest. The location and proper use of the defibrillator, bag valve mask and emergency medications were reviewed. This practice and review integrated previous classroom education with simulated clinic education.

\subsubsection{Application of ACLS “Hs and Ts" in a Q-sort style Worst-Case Scenario game}

Students returned to a table and were presented with a list of the ACLS "Hs and Ts": hypovolemia, hypoxia, hydrogen ion (acidosis), hyper-/hypokalemia, hypoglycemia, hypothermia, toxins, taponade (cardiac), tension pneumothorax, thrombosis (coronary and pulmonary), and trauma. They were than given a set of 7 cards. On each card was a medical diagnosis: diabetes, chest pain, pneumonia, chemical exposure, bleeding, sepsis, dehydration. Working together, students sorted the cards in the order of priority as if they were coming out of report. This learning game was called Worst - Case Scenario. The students asked questions of the faculty such as "When did the patient come in? Are they bleeding now?" etc. As they obtained new information, they applied the "H's and T's" to each diagnosis and demonstrated the ability to think ahead to the potential risk that each diagnosis posed to the patient. This activity provided students with the opportunity to use clinical reasoning and multiple ways of thinking. The ability to use clinical imagination to anticipate possible patient deterioration and the discussion of advocacy further aided formation of a professional RN identity.

\subsubsection{Code video and discussion of the roles of code team members}

Four minutes (5:42-9:40) of the American Heart Association's (AHA) Megacode and Team Resuscitation Concept ${ }^{[10]}$ video was shown to students. They were asked to identify the roles of the code team members. The focus of this activity was for students to identify the roles that were performed in an emergency and to begin to imagine themselves performing a role. Students and faculty discussed their preferred role as well as the skills needed for effective performance of each role. During the evaluation, one student wrote, "I liked how you admit that you didn't know everything as a new nurse... makes me encouraged that although we still have a lot to learn, we can do it." This activity provided a role model for students as they observed a code simulation and participated in the informal discussion and sharing of experiences that followed.

\subsubsection{Emergency simulation}

Finally, the students were given report on a simulated patient and performed the emergency simulation. Faculty instructed students to consider the holistic care of the patient and any family members during the code. The National League of Nursing (2005) scenario, Acute Myocardial In farction, with the simulated patient, Carl Shapiro, was implemented for aproximately 15 minutes. A thirty minute debriefing followed and the scenario was repeated to allow students to engage in different roles. There was a "family member" present during the code. Students were provided feedback regarding the effectiveness of compression and maintenance of airway as well as assessment and reassessment of the patient.

The debriefing also included discussion with students about the care of the "family" during the scenario. The scenario challenged the students' use of therapeutic communication with family during their performance of technical procedures. Students often thought that they communicated in a therapeutic and caring manner to the "family". However, this was not the view of either the faculty or the "family" actor. The "family" actor wrote on the evaluation, "Some people are more timid, and afraid to ask the family to kindly step back. Some people stand next to you and use their body to push you out of the way. Very few of the students knew that gently guiding the family out of the room or to a chair was the best way to handle the situation."

After the simulation debriefing, faculty handed students a three-dimensional model of a heart and asked students to identify generally where a myocardial infarction occurs. The faculty was surprised at the difficulty students had performing this activity. The follow-up discussion helped students use scientific reasoning to integrate course (pathophysiology) and clinical (symptoms and treatments) learning.

\subsubsection{Review of common emergency medications and their administration}

Although not initially part of the educational sequence it became apparent that students needed more understanding of the function of medications administered in cardiac emergencies. Due to time limitations, students were given cards 
with common cardiac medications and asked to sort them into two piles: medications that they knew and those they did not know. Time was spent reviewing the lesser known medications in relation to the scenario and cardiac function.

\section{Findings}

At the end of the educational sequence, students $(n=43)$ who agreed to participate in the study were asked to complete an evaluation. The evaluation included ranking and rating of five learning activities and two open-ended questions. Each of the learning experiences was ranked from 1 to 5 with 1 being most helpful and 5 as least helpful (see Table 1). The code simulation was most highly ranked. Students rated each learning activity using the following scale: Excellent-A, Good-B or Okay-C. Again, the code scenario received the most Excellent-A ratings (see Table 2).

Table 1: Frequency of ranking by educational activity $(\mathrm{n}=$ 38)

\begin{tabular}{llllll}
\hline & $\mathbf{1}$ & & & & $\mathbf{5}$ \\
& $\begin{array}{l}\text { Most } \\
\text { Helpful }\end{array}$ & $\mathbf{2}$ & $\mathbf{3}$ & $\mathbf{4}$ & $\begin{array}{l}\text { Least } \\
\text { Helpful }\end{array}$ \\
\hline $\begin{array}{l}\text { Code Practice } \\
\begin{array}{l}\text { Assessment } \\
\text { Practice }\end{array}\end{array}$ & 26 & 9 & 2 & 1 & 0 \\
$\begin{array}{l}\text { Critical Incident } \\
\text { Reading }\end{array}$ & 10 & 13 & 8 & 5 & 2 \\
$\begin{array}{l}\text { Worst-Case } \\
\text { Scenario Game }\end{array}$ & 0 & 3 & 14 & 8 & 12 \\
$\begin{array}{l}\text { AHA } \\
\text { Code Video }\end{array}$ & 1 & 9 & 7 & 18 & 4 \\
\hline
\end{tabular}

Table 2: Frequency of student rating for each learning activity $(\mathrm{n}=38)$

\begin{tabular}{llllll}
\hline & $\begin{array}{l}\text { Code } \\
\text { Practice }\end{array}$ & $\begin{array}{l}\text { Assessment } \\
\text { Practice }\end{array}$ & $\begin{array}{l}\text { Worst-Case } \\
\text { Scenario }\end{array}$ & $\begin{array}{l}\text { Critical } \\
\text { Incident }\end{array}$ & $\begin{array}{l}\text { AHA Code } \\
\text { Video }\end{array}$ \\
\hline $\begin{array}{l}\text { A } \\
\text { Excellent }\end{array}$ & 34 & 29 & 27 & 23 & 15 \\
$\begin{array}{l}\text { B } \\
\text { Good }\end{array}$ & 4 & 8 & 10 & 13 & 14 \\
C & 0 & 1 & 1 & 2 & 9 \\
Okay & & & & & \\
\hline
\end{tabular}

Students $(n=43)$ answered the first question, "What will you take from this experience?" A total of 83 responses were identified. Three major categories of responses emerged from the comments (see Table 3). The first was 'knowing how' (18), the second was 'increasing confidence' (18), the third was 'understanding roles' (17). Additional comments were related to specific aspects of the nurses' response to emergencies and were categorized as 'code prevention' (7), 'prioritizing/organization/preparation' (5), 'assessment/intuition' (5), 'calling for help' (3), and 'medication' (2). Eight comments did not fall into any of these categories.

Finally, students $(n=36)$ answered the final question, "What suggestions do you have for future groups?" Answers to this question were categorized as related to the learning activities themselves or to the implementation of the learning sequence. The most frequent recommendations were in relation to the code scenario and were categorized as 'Better explanation', 'More practice in different roles', 'To have different types of scenarios and assessments'. Other comments were directed at the assessment practice such as "allow each student time to assess the SimMan and evaluate breath sounds, heart sounds, questioning, etc." Three students wanted more time, "More time! 3 hours would be great!" and one did not, "I thought it was the perfect amount of time to talk, learn, and practice scenarios. I enjoyed the different activities".

Table 3: What will you take from this experience?

\begin{tabular}{|c|c|}
\hline $\begin{array}{l}\text { Category (Number of } \\
\text { comments) }\end{array}$ & Example \\
\hline Knowing How (18) & $\begin{array}{l}\text { "The basics of what to do in a code situation." } \\
\text { "I now feel comfortable enough and } \\
\text { understand how to intervene during an } \\
\text { emergency situation." }\end{array}$ \\
\hline $\begin{array}{l}\text { Increasing } \\
\text { Confidence (18) }\end{array}$ & $\begin{array}{l}\text { "I will bring more skill, knowledge, and more } \\
\text { confidence into a code situation." }\end{array}$ \\
\hline $\begin{array}{l}\text { Understanding } \\
\text { Roles (17) }\end{array}$ & $\begin{array}{l}\text { "How a code works and everyone's role in } \\
\text { the code." }\end{array}$ \\
\hline Prevention of Code (7) & $\begin{array}{l}\text { "I feel like I have a much clearer idea of the } \\
\text { series of events that occur in a code and the } \\
\text { importance of working to prevent a code.” } \\
\text { "I now know some of the warning signs of } \\
\text { critical situations \& feel more comfortable } \\
\text { making changes to prevent a code.” }\end{array}$ \\
\hline $\begin{array}{l}\text { Prioritizing/organizati } \\
\text { on/preparation (5) }\end{array}$ & $\begin{array}{l}\text { "Prioritization during emergency scenarios." } \\
\text { "I have learned how important it is to be } \\
\text { organized and know your role during an } \\
\text { emergent situation.” }\end{array}$ \\
\hline $\begin{array}{l}\text { Assessment/ } \\
\text { intuition (5) }\end{array}$ & $\begin{array}{l}\text { "Be prepared. Assess, go with your gut. } \\
\text { Prevention is key!” }\end{array}$ \\
\hline Calling for help (3) & $\begin{array}{l}\text { "No hesitation-you must ACT. Being } \\
\text { assertive and listening to directions is crucial } \\
\text { in a code." }\end{array}$ \\
\hline Medication (2) & $\begin{array}{l}\text { "I will have more confidence in the code } \\
\text { situation. I have practice in the role of giving } \\
\text { emergency meds." }\end{array}$ \\
\hline
\end{tabular}

Two faculty members were present during the emergency simulation. For consistency, one faculty member was at all eleven of the simulations. Other faculty participated in 1 to 4 simulations. The answer from a clinical faculty member to the question, "What will you take from this experience?" was simply, "Re-teach students about the location and use of the crash cart each semester. I will assign a student to check the crash cart, defibrillator, and suction equipment each clinical day."

Faculty answers to the question, "What suggestions do you have for future groups?" included, "The simulation was excellent. A suggestion could be having two different emergency simulations, extending the time of the lab for both simulations." "I wonder if the small group aspects of the 
simulation could be performed as part of a post conference or in the classroom. Then more time in the lab could be spent on the simulation."

\section{Discussion}

This case example of a learning sequence illustrates the characteristics of pre-briefing educational activities and benefits of engaging in an emergency simulation experiences. Researchers ${ }^{[11-18]}$ have established the importance of clear objectives for each simulation encounter and are beginning to study the content and design of pre-briefing activities. We discuss our findings and study limitations in the context of their reports in relation to simulation design and use of pre-briefing, affective learning experiences, faculty facilitator effects, student performance, student selfassessment and student-perceived benefits.

Waxman $^{[11]}$ developed guidelines for effective evidencebased simulation scenarios. These guidelines included the creation of clear objective-driven scenarios with a template for scenario development. Waxman ${ }^{[11]}$ included psychomotor skills and cognitive competencies that the learner must possess prior to the scenario in the prescenario template. Our scenario included objectives and activities completed in a structured learning environment. Faculty participants suggested that some of the learning activities from this sequence may be better moved to another setting (e.g. larger classroom). A benefit to including the prescenario learning activities in the lab setting was that it allowed faculty to assess student readiness for the scenario and evaluate student engagement.

Berragan $^{[12]}$ espouses the use of expansive learning in simulation including recognition of the affective element of performance. The use of situated cognition and discussion of feelings related to involvement in an emergency simulation contributed to the strength of this learning sequence. Husebo, Friberg Soreide and Rystedt ${ }^{[13]}$ specifically identified the importance of the faculty instructions to the participants in emergency simulations. These researchers identified the importance of demonstrating the position of the emergency responder and the role of the faculty facilitator's ability to explain differences among real and simulated experiences. In our experience, providing explicit instruction to students about the simulation environment improved their performance in the simulation.

Brydges, Carnahan, Rose, and Dubrowski ${ }^{[14]}$ examined student skill performance in simulation. They demonstrated improved transfer of skills a week after training among selfregulated learners who progressed from low to mid to higher fidelity practice environments. Due to time constraints, faculty adhered to the time allotted for each learning activity. Some students reported the desire for more time to interact with the learning activities while others found the timing to be "just right." Students' learning may benefit from com- pleting the learning sequence activities at their own pace and determining when they are ready to perform the simulation. In this way, using self-regulated prescenario learning activities may improve students' ability to retain and transfer the skills into their nursing practice.

Our scenario included the expectation that the student would communicate therapeutically with the "family" during the simulation. However, this was not a written objective and there was not a learning activity to draw the student's attention to the role of the nurse with "family" or other bystanders in the emergency environment briefing. Eggenberger, Keller and Locsin ${ }^{[15]}$ provide an excellent example of using simulation to study caring in a variety of ways and specifically explored caring behaviors in emergent situations.

Kelly, Hager and Gallagher ${ }^{[16]}$ reported on students' perception of the benefits to their clinical judgment following a simulation of a deteriorating patient. Students in the study conducted by Kelly et al. placed the debriefing activity and guidance from the academic more highly than students in our study. This difference may have been due to study methods. Students in the Kelly et al. study used a 5-point rating scale (range 3.23 to 4.02) to measure each activity. Our students' rated each activity as 'excellent', 'good,' or 'okay.' Both studies found that students rated all activities as beneficial to meet learning objectives. However, our students also rank ordered each of the five activities against each other. Using forced rank order of each item may be a more descriptive measure of preference than using a rating scale alone.

Baptista, Martins, Pereira, and Mazzo ${ }^{[17]}$ performed a systematic review of English language and published studies from 2005 to 2011 using EBSCOhost and "high-fidelity simulations" in the title with the following keywords: AND simulation; AND nursing; AND students; OR perceptions; and OR education. The authors describe their methodology for extracting nine articles. These nine articles were then analyzed for core themes. The core themes identified included: Satisfaction, Learning and motivation, Realism, Self-Confidence, Technical skills, Reflection on action, and Transfer of skills. Baptista et al. ${ }^{[17]}$ 's core themes were consistent with those found in our study. Themes identified in our study related to the simulation experience included 'knowing how' (18), 'increasing confidence' (18), and 'understanding roles' (17). Knowledge related themes specific to the emergency included 'code prevention' (7), prioritizing/organization/preparation' (5), 'assessment/intuition' (5), 'calling for help' (3), and 'medication' (2). Our analysis supports the work of Baptista et al..$^{[17]}$ by not identifying any novel themes.

A limitation of this case descriptive report is that the acquisition of the skill and knowledge necessary for the emergency response was not evaluated. Future research to measure stu- 
dent preparation for clinical emergencies is needed and may be addressed with the appropriate use of pre-briefing. The use of pre-briefing to establish a situated cognition for the emerging professional is an example of linking and transitions as described by Cordeau. ${ }^{[17]}$ Our study revealed that student performance of caring behaviors were not addressed in our pre-briefing. Therefore, our students did not link their knowledge of caring behaviors to the scenario. Cordeau ${ }^{[18]}$ used grounded theory methods to reveal how the process of caring as a professional nurse unfolds during simulation experiences. Future use of this simulation would benefit from an activity demonstrating the use of caring behaviors in emergency simulation.

\section{Conclusion}

This two-hour educational sequence supports the call by Benner et al. ${ }^{[9]}$ to transform the practice of nursing education by exploring the recommended processes and responses of students and faculty to a simulation experience. The importance of pre-briefing was evident in the performance of the simulation. Two additional activities need to be further developed in order to strengthen this learning sequence. Firstly, adding the review of emergency cardiac medications with student prepared drug cards may be beneficial. Secondly, a review of therapeutic communication and the role of caring for family may be added to the discussion of roles during an emergency. Finally, future use of these objectives may be implemented in an open-ended progressive (low to highest fidelity) structure.

This two-hour educational sequence allowed students and faculty to be engaged in multiple ways of thinking and application of theory to practice. Prior to the implementation of the sequence, faculty commented that students had "learned" the emergency content about to be applied during the simulation. However, student performance and questions asked during the pre-briefing indicated to faculty that the classroom learning had not been meaningfully retained. Students identified 'knowing how', 'increasing confidence' and 'understanding roles' as what they would take from the experience. Students rated the simulation itself as most helpful. Self-evaluation by clinical faculty resulted in plans to include a weekly review of emergency equipment in clinical. Self-evaluation by didactic faculty resulted in planning to include clinically relevant content to demonstrate theoretical concepts in classroom education. Incorporating Benner et al. ${ }^{[9]}$ 's transformational educational goals strengthened the educational sequence and engaged students in the learning experience. The intentional use of pre-briefing activities employed clinical imagination to strengthen formation of a professional identity. The educational sequence provided the opportunity for a deeper understanding, and the application and integration of course concepts.

\section{Conflicts of Interest Disclosure}

The author declares that there is no conflict of interest statement.

\section{References}

[1] Mills J, West C, Langtree T, et al. 'Putting it together': Unfolding case studies and high-fidelity simulation in the first-year of an undergraduate nursing curriculum. Nurse Educ Pract [Internet]. 2013; 14: 12-16. http://dx.doi.org/10.1016/j.nepr.2013.06.003

[2] Parker BC, Myrick F. A critical examination of high-fidelity human patient simulation within the context of nursing pedagogy. Nurse Educ Today. 2008; 2: 322-329.

[3] Tosterud R, Hedelin B, Hall-Lord ML. Nursing student's perceptions of high- and low-fidelity simulation used as learning methods. Nurse Educ Pract [Internet]. 2013; 13: 262-270. http://dx.doi .org/10.1016/j.nepr.2013.02.002

[4] Levett-Jones T, Lapkin S. A systematic review of the effectiveness of simulation debriefing in health professional education. Nurse Educ Today. 2014; 34: e58-e63. PMID:24169444 http://dx.doi.org /10.1016/j.nedt.2013.09.020

[5] Lavoie P, Pepin J, Boyer L. Reflective debriefing to promote novice nurses' clinical judgment after high-fidelity clinical simulation: A pilot test. Dynamics. 2013; 24(4): 36-41. PMID:24616950

[6] Page-Cutrara K. Use of Prebriefing in Nursing Simulation: A literature review. J Nurs Educ [Internet]. 2014; 53(3): 136-141. http: //dx.doi.org/10.3928/01484834-20140211-07

[7] Fisher D, King L. An integrative literature review on preparing nursing students through simulation to recognize and respond to the deteriorating patient. J Adv Nurs [Internet]. 2013; 69(11): 2375-2388. http://dx.doi.org/10.1111/jan.12174
[8] Bogossian F, Cooper S, Cant R, Beauchamp A, Porter J, Kain V, et al., The FIRST2ACT ${ }^{\mathrm{TM}}$ Research Team. Undergraduate nursing students' performance in recognising and responding to sudden patient deterioration in high psychological fidelity simulated environments: An Australian multi-centre study. Nurse Educ Today [Internet]. 2014 May; 34 (5): 691-696. http://dx.doi.org/10.1016 /j.nedt.2013.09.015

[9] Benner P, Sutphen M, Leonard V, Day L. Educating Nurses: A Call for Radical Transformation. San Francisco: Josey-Bass; 2010.

[10] Gerik J. Megacode and Team Resuscitation Concept. USA: American Heart Association [Internet Video]. 2012, July 10. Available from: http: //www . youtube. com/wat ch?v=6kh0CLu7bro

[11] Waxman KT. The development of evidence-based clinical simulation scenarios; Guidelines for nurse educators. J Nurs Educ. 2010; 49(1): 29-35. http://dx.doi.org/10.3928/01484834-20090 916-07

[12] Berragan L. Conceptualising learning through simulation: An expansive approach for professional and personal leraning. Nurs Educ Prac. 2013 13; 250-255. http://dx.doi.org/10.1016/j.nep r.2013.01.004

[13] Husebo SE, Friberg F, Soreide E, Rystedt H. Instructional problems in briefings: How to prepare nursing studnets for simulation -based cardiopulmonary resuscitation training. Clin Sim Nurs. 2010; 8: e307-3318. http://dx.doi.org/10.1016/j.ecns. 20 10.12.002

[14] Brydges R, Carnahan H, Rose D, Dubrowski A. Comparing self-guided learning and educator-guided learning formats for simulation-based clinical training. J Advan Nurs. 2010; 66(8): 
1832-1844. PMID:20557388 http://dx.doi.org/10.1111/j $.1365-2648.2010 .05338 . x$

[15] Eggenberger T, Keller K, Locsin RC. Valuing caring behaviors within simulated emergent nursing situations. International J Human Caring. 2010; 14(2): 23-29.

[16] Kelly M, Hager P, Gallagher R. What matters most? Students' rankings of simulation components that contribute to clinical judgment. J Nurs Educ. 2014; 53(2): 97-101. PMID:24444013
[17] Baptista R, Martins J, Pereira M, Mazzo A. High-fidelity simulation in the nursing degree; Gains perceived by students. Referência J Nurs. 2014; 4(1): 131-140. http://dx.doi .org/10.12707/RI II13169

[18] Cordeau MA, Linking the transition: A substantive theory of highstakes clinical simulation. Advan Nurs Sci. 2012; 35(3): E90-E102. http://dx.doi.org/10.1097/ANS. 0b013e3182614f 